\title{
Acquisition of the conditioned eyelid response under different ready-signal conditions'
}

\author{
ROBERT H. DUFORT AND HOWARD A. ROLLINS ${ }^{2}$ \\ WAKE FOREST COLLEGE
}

\begin{abstract}
Abstraet
Four groups were run in an eyelid conditioning experiment under different combinations of information given about, and instructions to blink to, a stimulus preceding each trial (ready signal). The group conditioned without a ready signal was superior to the other three groups, regardless of whether or not Ss in these groups blinked to the ready signal or were given information about it in the instructions.
\end{abstract}

\section{Problem}

Price et al (1964) reported a study testing the hypothesis that the inferior performance in eyelid conditioning typically found in Ss given a ready signal before each trial is due to suppression of the CR by response inhibition generated by a blink to the ready signal. They found that a group conditioned without a ready signal was superior to two groups conditioned with a verbal ready signal, in one of which Ss were instructed to blink to the signal while in the other they were not so instructed. The two signal groups did not differ significantly, although the no-blink group performed at a higher level over the last 60 trials. They concluded that response-produced inhibition from the blink could not account for the inferior performance associated with the ready signal.

In view of the consistently, although not significantly, better performance of the no-blink signal group, additional evidence on the role of the blink and the generality of these results is needed. In the present experiment, three groups were run under conditions similar to those of Price et al. The major procedural difference was the use of a buzzer instead of a verbal signal for the two ready-signal groups. The buzzer was used not only because it has been employed as a ready signal in previous research (e. g., Dufort \& Kimble, 1958; McAllister, 1953), but also because it permitted a fourth group to be added to the Price et al design. This group received the buzzer before each trial; however, the instructions did not give any information about it, and Ss were not instructed to blink to it. In many previous studies, either by using the verbal "ready" as the signal or by giving Ss instructions which label some other stimulus (e. g., a buzzer) as a ready signal, identification of the nature of the signal occurs for $S$. The fourth group was run to compare the performance of Ss for whom an unidentified stimulus to which they do not blink precedes each trial with that of Ss who have the stimulus identified and who blink to it. Merhod

The Ss were 76 male students who participated as part of a course requirement. Nineteen Ss were ran- domly assigned to each of the four groups.

The apparatus was similar to that used in the Yale replication of the studies reported by Dufort \& Kimble (1958). Briefly, S sat in an adjustable barber's chair in a soundproof chamber. The CS was an increase in brightness from a between-trials level of .24 apparent $\mathrm{ft}-\mathrm{c}$ to $\mathbf{1 . 0 8}$ apparent $\mathrm{ft-c}$ of a circular milk-glass disc. The UCS was an air puff of 3 psi delivered to the right eye. The duration of the CS was $560 \mathrm{msec}$. The UCS was delivered during the last $60 \mathrm{msec}$. of the CS, thus providing an interstimulus interval of $500 \mathrm{msec}$. Eyelid responses were recorded by a pen driven by a microtorque potentiometer mechanically connected to S's right eyelid. A CR was defined as deflection of the response pen of $1 \mathrm{~mm}$ or more between 200 and 500 msec. after CS onset.

All groups received 70 conditioning trials with randomly varied intertrial intervals of 15,20 , or $25 \mathrm{sec}$. For the ready-signal groups, a buzzer of 1-sec. duration preceded each trial by randomly varied intervals of 2,3 , or 4 sec. Neutral instructions were given to all groups and were identical except for the part about the ready signal for groups receiving it. Group A was conditioned without the ready signal. Group B received the buzzer; but the instructions gave no information about it, and Ss were not told to blink to it. Group C received the buzzer, identified as a ready signal, but were not instructed to blink to it. Group $D$ received the buzzer; for these Ss it was identified as a ready signal, and they were told to blink once upon hearing it. Groups A, C, and D are similar, respectively, to Groups NR, $R$, and $R B$ in the Price et al study.

\section{Results and Diseussion}

Figure 1 presents acquisition curves for all groups. Analysis of variance on percent CR yielded a significant group effect when the analysis was conducted for all 70 trials $(p<.05)$ and for the last block of 10 trials $(p<.025)$. Individual group comparisons showed that Group A was superior to Groups B, C, and D $(p<.05$ in each case for all 70 trials; $p<.025$ in each case for last 10 trials), but that the latter three groups did not differ significantly among themselves.

The results for Groups A, C, and D confirm the findings of Price et al and extend their generality to acquisition with a buzzer as the ready signal. The no-blink signal group (Group C) did show somewhat higher performance than the blink, signal group (Group D) during the first 30 trials, but the curves for these two groups converged toward similar asymptotes. On 


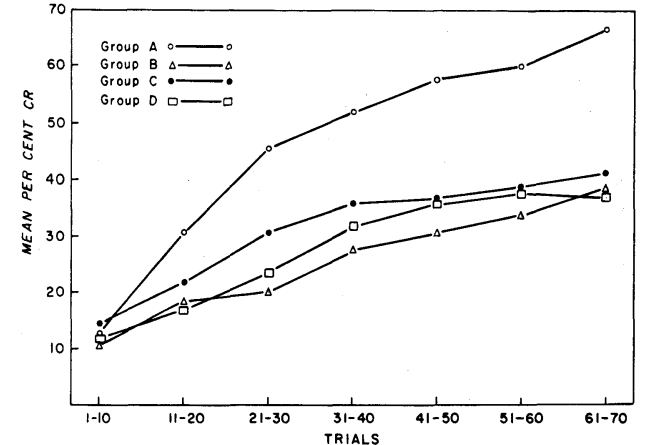

Fig. 1. Acquisition curves for all four groups as a function of blocks of ten trials.

the other hand, Price et al found their no-blink signal group (Group R) to be somewhat inferior to their blink, signal group (Group RB) on the first 20 trials and to show higher performance over the last 60 trials. In neither experiment, however, did these two groups differ significantly. The combined evidence, then, points to the conclusion that the blink is not differential with respect to the inferior performance of ready-signal groups. We are inclined to agree with Price et al that more complex factors, such as lowered drive resulting from the signal or competing responses initiated by the signal, are invalved.

Finally, the performance of Group B was notdifferent from that of the other two signal groups. Group B received the buzzer but was not given any information about it. If identification through instructions or through the use of "ready" as the signal is involved in the inferior performance of signal groups, Group B might have been expected to perform at a higher level than Groups C and D. The fact that it did not shows that simply having the stimulus precede the trial is sufficient to produce inferior performance.

\section{References}

Dufort, R. H., \& Kimble, G. A. Ready signals and the effect of interpolated UCS presentations in eyelid conditioning. $J$. exp. Psychol., 1958, 56, 1-7.

McAllister, W. R. Eyelid conditioning as a function of the CS-US interval. J. exp. Psychol., 1953, 45, 417-422.

Price, L. E., Vandament, W. E., \& Abbott, D. W. Effects of ready signal condition on acquisition and extinction of the conditioned eyelid response. J. exp. Psychol., 1964, 68, 516-518.

\section{Notes}

1. This research was supported by a grant from the Graduate Council of Wake Forest College.

2. Now at University of California, Los Angeles. 